\title{
Metastatic carcinoma of the iris simulating iridocyclitis
}

\author{
JOHN J. WOOG,${ }^{1}$ JEREMY CHESS,${ }^{1}$ DANIEL M. ALBERT,${ }^{1}$ DAVID K. DUEKER,${ }^{2}$ \\ FRANK G. BERSON,$^{13}$ AND JOSEPH CRAFT ${ }^{1}$
}

From the ${ }^{1}$ Harvard Medical School, Massachusetts Eye and Ear Infirmary, Boston; ${ }^{2}$ Institute of Ophthalmology, University of Missouri Medical Center, Columbia; and ${ }^{3}$ Harvard Medical School, the Charles A. Dana Research Institute, Beth Israel Hospital, Boston USA

SUMMARY A 46-year-old woman with a history of breast carcinoma and no known metastatic disease presented with iridocyclitis and secondary glaucoma. Intraocular inflammation and pressure elevation persisted despite standard medical therapy, and paracentesis was performed. Cytological examination of the aspirate revealed adenocarcinoma. Subsequent studies disclosed no evidence of extraocular metastasis. Two courses of radiation therapy to the involved eye resulted in a dramatic reduction in intraocular inflammation and allowed temporary control of the intraocular pressure. Ultimately, however, progressive glaucoma necessitated enucleation. This case confirms previous statements that iridocyclitis may be the initial clinical manifestation of metastatic malignancy. In addition, this report emphasises the importance of paracentesis in the diagnostic evaluation of selected cases of anterior uveitis of unknown aetiology.

Ocular and orbital metastases are well known complications of malignant disease. From $4 \cdot 7 \%^{1}$ to $12 \%^{2}$ of patients dying of generalised malignancy may have clinical or pathological evidence of ocular or orbital involvement. Indeed, metastatic carcinoma may well be the most common form of intraocular malignancy. ${ }^{3}$ The incidence of apparent metastatic disease has been noted to vary significantly with respect to location within the eye and orbit. ${ }^{4}$ Anterior segment metastasis was relatively uncommon in that series, predominating in only $11.4 \%$ of the patients studied; of these patients, at least $60 \%$ had decreasing visual acuity or a visible iris or ciliary body mass as the presenting sign of ophthalmic involvement.

We describe here a less common mode of presentation of carcinoma metastatic to the anterior segment, namely that of persistent anterior segment inflammation. In addition, this report emphasises the importance of paracentesis in the diagnostic evaluation of anterior uveitis of unknown aetiology.

\section{Case report}

A 46-year-old woman presented with a history of mild injection and blurring of vision of the right eye of 2

Correspondence to Daniel M. Albert, MD, Massachusetts Eye and Ear Infirmary, 243 Charles Street, Boston, MA 02114, USA. weeks' duration. Her past ocular history was unremarkable. Her past medical history was notable for the diagnosis 14 months previously of poorly differentiated adenocarcinoma of the left breast metastatic to left axillary lymph nodes. An examination including bone scan, skeletal survey, liverspleen scan, hepatic ultrasonography, and automated chemistry screen disclosed no other evidence of metastatic disease. The patient underwent local excision of the tumour and involved lymph nodes and subsequently received radiation therapy by external beam and implant to the left breast, left axilla, left supraclavicular region, and excisional biopsy site. She then received a 6-month course of adjuvant chemotherapy with cyclophosphamide, methotrexate, and 5-fluorouracil. Serial examinations and laboratory studies following the completion of therapy demonstrated no evidence of recurrence. The patient denied having had other significant medical illnesses including hypertension, diabetes mellitus, tuberculosis, sarcoidosis, syphilis, and collagen vascular disease.

Initial ocular examination revealed visual acuity LE 6/9; RE 6/15 improving with pinhole to $6 / 9$. Extraocular motions were full. The pupils were $3 \mathrm{~mm}$ in diameter and were briskly reactive to light; the right pupil, however, had an area of irregularity at 5 o'clock (Fig. 1). Mild ectropion was noted in this area 


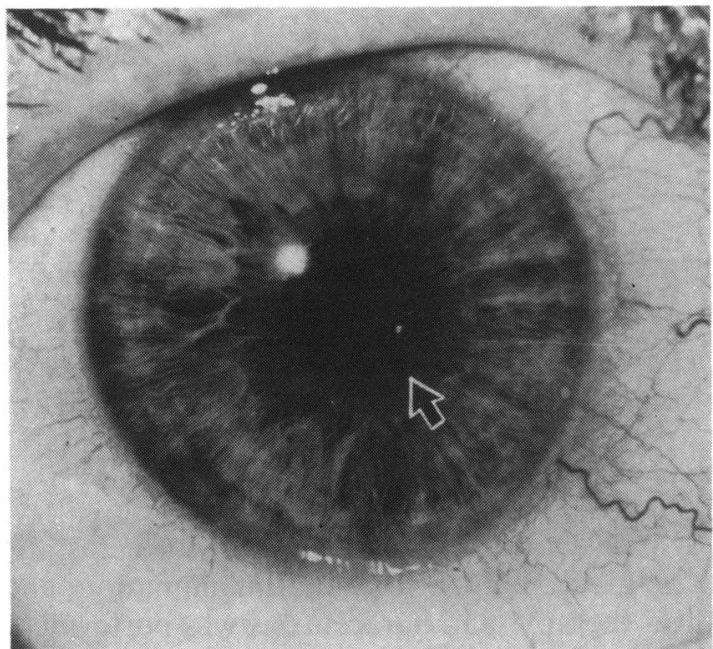

Fig. 1 There is an area of pupillary irregularity at 5 o'clock (arrow). No iris mass is evident.

as well. Slit-lamp examination revealed mild injection of the right eye with a $2+$ anterior chamber reaction. No keratic precipitates were seen, and the iris and lens were normal. Applanation tensions were RE 35 $\mathrm{mmHg}$; LE $18 \mathrm{mmHg}$. Gonioscopy of the right eye revealed that the angle was open without mass lesion or cellular precipitates. Funduscopic examination of the right eye revealed a small white intraretinal lesion resembling a nerve fibre layer infarct superotemporal to the disc in the right eye (Fig. 2). Biomicroscopic, gonioscopic, and ophthalmoscopic findings in the left eye were all within normal limits. A clinical diagnosis of iridocyclitis of the right eye was made.

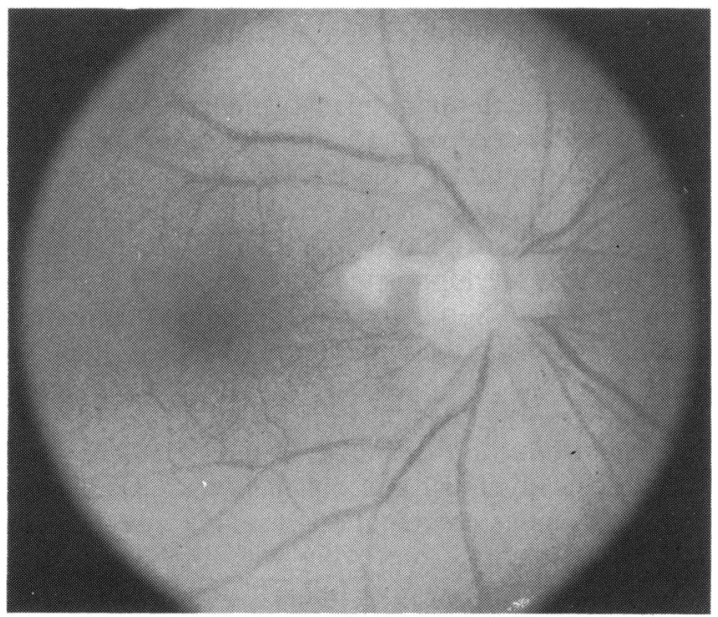

Fig. 2 A white intraretinal lesion resembling a nerve fibre layer infarct was present superotemporal to the disc in the affected eye.

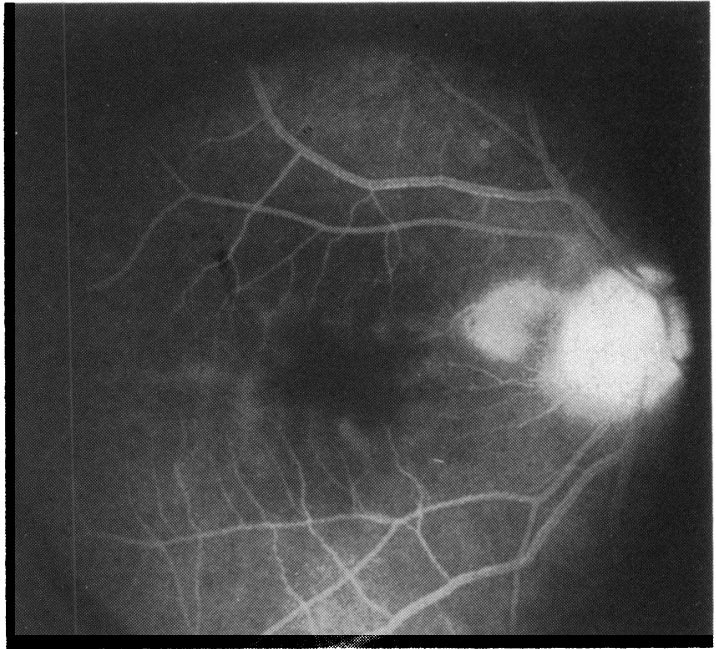

Fig. 3 Spotty hyperfluorescence in the macular area is consistent with macular oedema.

Therapy was initiated with scopolamine and topical prednisolone phosphate. When the patient initially came under our care 2 days later, best corrected visual acuity $\mathrm{RE}$ was reduced to $6 / 15$, and the anterior chamber reaction was unchanged despite therapy. The applanation tension $\mathrm{RE}$ was $46 \mathrm{mmHg}$; repeat gonioscopy was negative. Macular oedema was noted on examination of the posterior pole. Timolol and acetazolamide were added to the medical regimen with a reduction in intraocular pressure to $28 \mathrm{mmHg}$. Examination 2 days later, however, revealed an applanation tension RE of $40 \mathrm{mmHg}$. Fine keratic precipitates were observed, and deposits of pigment and inflammatory cells were present on the anterior lens capsule. The anterior chamber inflammatory response was unchanged. Medical therapy was continued and dipivalyl epinephrine was started for further control of the intraocular pressure in the right eye. Diagnostic studies (including chest roentgenography, complete blood count, erythrocyte sedimentation rate, automated serum chemistry profile, rheumatoid factor, antinuclear antibody, complement level, angiotensin converting enzyme level, and intradermal testing for tuberculosis) were performed, with negative results. Fluorescein angiography of the right eye showed blocked hyperfluorescence in the region of the white intraretinal lesion, consistent with a nerve fibre layer infarct, and spotty hyperfluorescence in the macular area, consistent with macular oedema (Fig. 3).

Subsequent examination revealed visual acuity $R E$ of 6/21 with applanation tension RE of $43 \mathrm{mmHg}$. A $2+$ cellular response was evident in the anterior chamber. Gonioscopy now showed a dense layering 


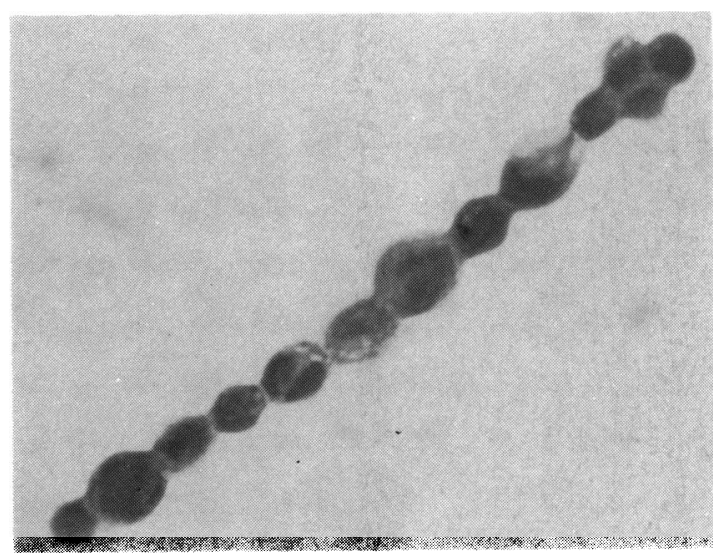

Fig. 4 This cytocentrifugation preparation demonstrates tumour cells arranged in clusters and columns. Cytological characteristics are compatible with a diagnosis of metastatic adenocarcinoma. (Haematoxylin, $\times 157$ ).

of cells over the inferior section of the angle. In view of the persistence of intraocular inflammation and pressure elevation unresponsive to vigorous medical therapy the patient was admitted to the Massachusetts Eye and Ear Infirmary and diagnostic paracentesis was performed. Corneal entrance wounds were created at 4 and 8 o'clock with a Wheeler knife. A 30 gauge needle attached to a $1 \mathrm{ml}$ tuberculin syringe was then introduced through the nasal opening and $0 \cdot 1 \mathrm{ml}$ of aqueous was aspirated and sent to pathology. A second 30 gauge needle was introduced simultaneously through the temporal opening and the anterior chamber was reformed with normal saline. A second $0 \cdot 1 \mathrm{ml}$ aliquot of fluid was then withdrawn through the nasal wound and was sent for pathological examination. A cannula was introduced through the temporal wound and the anterior chamber was reformed and deepened with a slow infusion of normal saline. $2 \mathrm{ml}$ of fluid was withdrawn concurrently for microbiological studies.

Cytological analysis of the aqueous was performed with Millipore filtre ${ }^{5}$ celloidin bag, ${ }^{6}$ and cytocentrifugation techniques. ${ }^{7}$ The cytocentrifugation preparation revealed pleomorphic cells with a high nuclear-cytoplasmic ratio. The cells were arranged in elusters and columns (Fig. 4). The cytological characteristics were compatible with a diagnosis of metastatic adenocarcinoma.

The patient subsequently returned to her oncologist, who found no clinical evidence of extraocular metastatic disease. Radionuclide bone imaging, computed tomography of the brain and orbits, and a serum chemistry profile were normal. Systemic tamoxifen citrate therapy was initiated, and radiation therapy consisting of $3000 \mathrm{R}(774 \mathrm{mC} / \mathrm{kg})$ delivered by external beam was administered to the right eye.

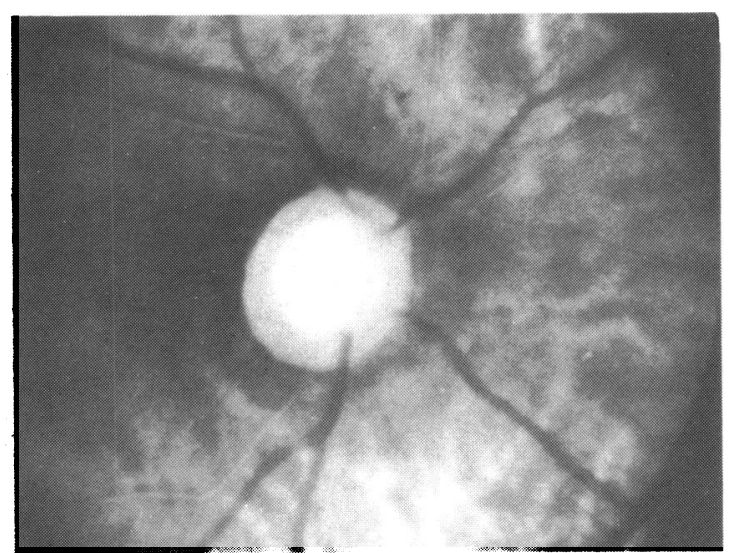

Fig. 5 The white intraretinal lesion was smaller following radiation therapy.

Re-examination revealed a marked decrease in anterior chamber inflammation, with a return of visual acuity and intraocular pressure RE to nearnormal levels. The intraretinal lesion was smaller in size (Fig. 5).

Two months after completion of the course of radiation therapy the patient noted recurrent blurring of the vision in her right eye. A $2+$ anterior chamber reaction was present, and the applanation tension was elevated despite maximal medical

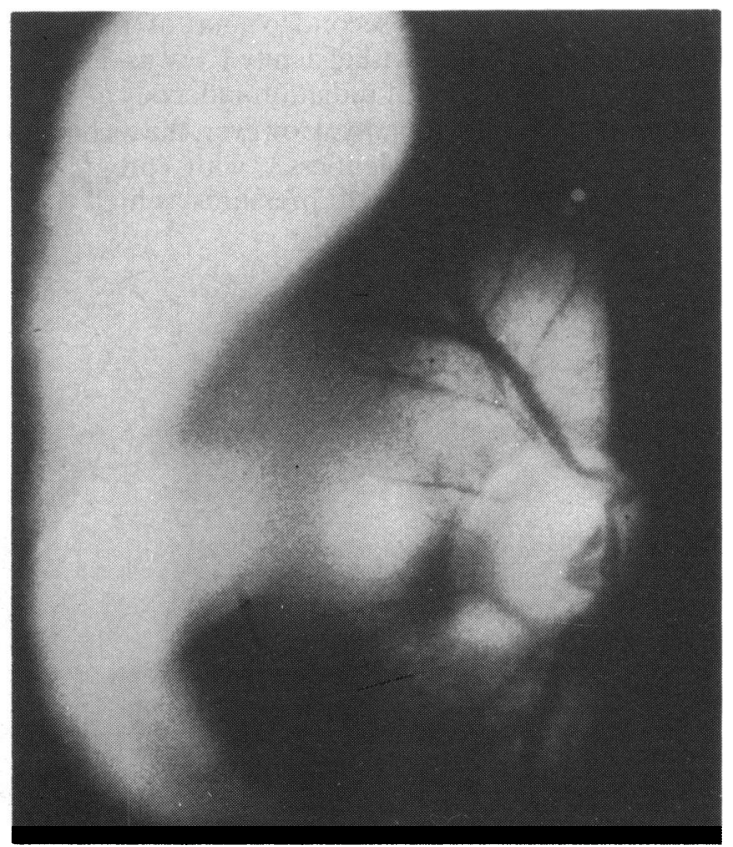

Fig. 6 A second intraretinal lesion was noted at the inferotemporal margin of the disc 2 months after the completion of radiation therapy. 


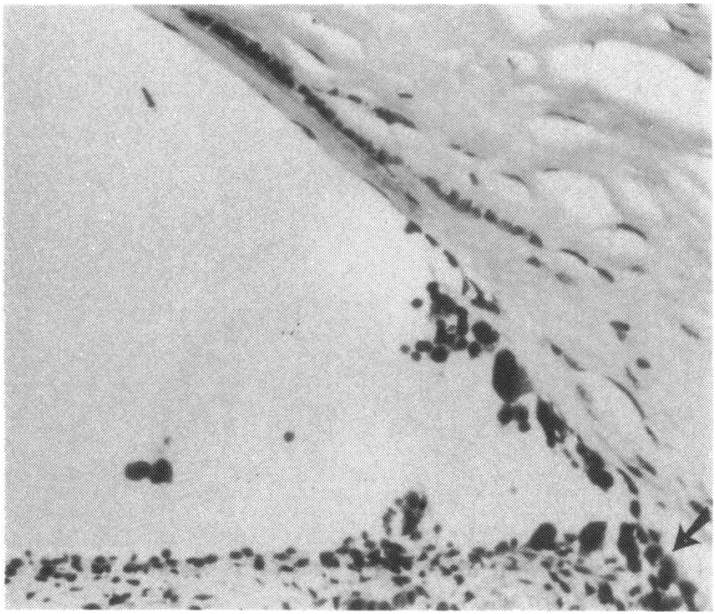

Fig. 7 Anaplastic cells are noted on the anterior surface of the iris, in the iridocornal angle, and along the posterior aspect of Descemet's membrane. Peripheral anterior synechiae are present (arrow). (Haematoxylin and eosin, $\times 85)$.

therapy. Funduscopic examination revealed a new white intraretinal lesion inferotemporal to the disc (Fig. 6). The patient received a second course of radiation therapy to the right eye, with a reduction in intraocular pressure to $24 \mathrm{mmHg}$ and disappearance of the new intraretinal lesion. Two months following the completion of the second course of radiation therapy best-corrected visual acuity RE was $6 / 9$, and there was no evidence of radiation-induced cataract, keratopathy, or retinopathy. However, the secondary glaucoma became relentless, with progressive cupping and field loss due to pressures as high as 47

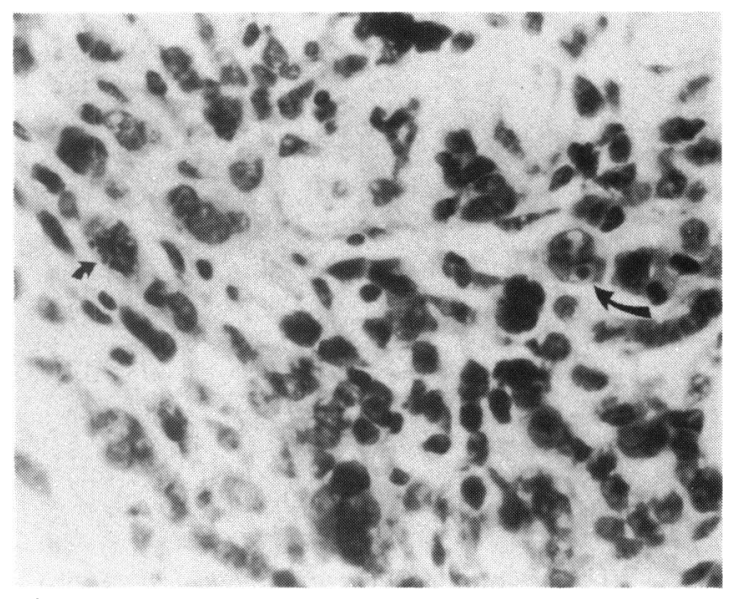

Fig. 9 Neoplastic cells show hyperchromasia and extreme pleomorphism with marked variation in nuclear size and nucleoli cytoplasmic ratio. An occasional mitotic figure is noted (small arrow) and a binucleate cell with prominent nucleoli is seen (large arrow). (Haematoxylin and eosin, $\times 125$ ).

mmHg despite maximum medical therapy. An argon laser trabeculoplasty to the superior 6 clock hours of open angle failed to lower the intraocular pressure. With the vision decreased to $6 / 60$ and the prognosis for useful vision nil, the patient underwent enucleation, which was performed 15 months after her initial presentation with iridocyclitis.

Pathological examination of the enucleated specimen revealed infiltration of the peripheral cornea by cells with hyperchromatic nuclei and scant cytoplasm in an 'Indian file' fashion (Figs. 7, 8). Collections of similar cells were noted on the
Fig. 8 Malignant cells infiltrate between the corneal stromal lamellae in an 'Indian file' fashion. (Haematoxylin and eosin, $\times 100$ ).

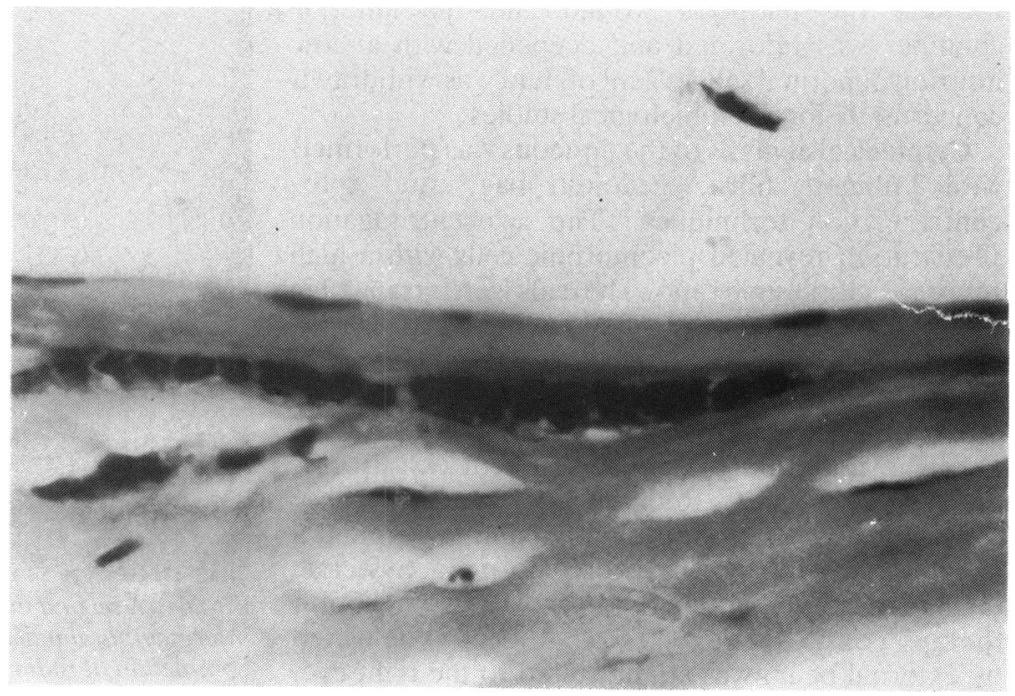




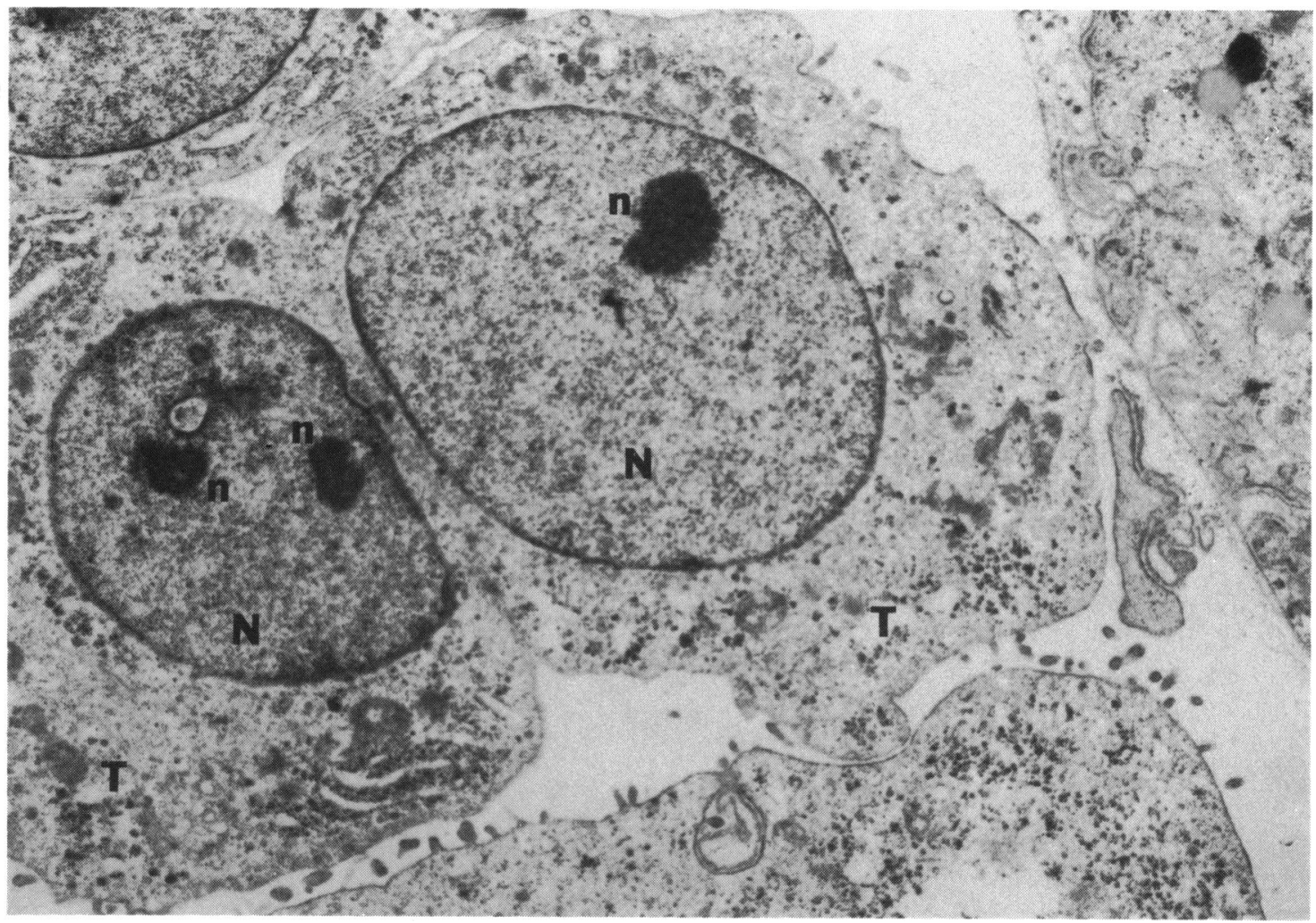

Fig. 10 On ultrastructural examination tumour cells $(\mathrm{T})$ assume a cohesive appearance. Large cell nuclei $(\mathrm{N})$ with prominent electron-dense nucleoli $(\mathrm{n})$ are present $(T E M, \times 4420)$.

peripheral iris and ciliary body. At higher magnification (Fig. 9) these cells displayed marked variation in nuclear size and shape and nuclear-cytoplasmic ratio. Neoplastic cells were also noted in the anterior chamber. Transmission electron microscopy confirmed the presence of cohesive cells with large nuclei and prominent nucleoli (Fig. 10). Occasional binucleate cells were identified (Fig. 11).

\section{Discussion}

Metastatic lesions involving the anterior segment have been described in association with a variety of solid and haematological neoplasms since the initial description of the metastatic carcinoma to the iris by Proctor and Verhoeff in $1907 .{ }^{8}$ Primary malignancies with reported metastases to the iris or ciliary body are summarised in Table 1. Uveal involvement may be a particularly prominent feature of reticulum cell sarcoma. ${ }^{9}$ In a recent review of 227 cases of metastatic carcinoma to the eye and orbit Ferry and Font identified 26 patients $(11.4 \%)$ in whom anterior segment involvement predominated. ${ }^{3}$. Common presenting signs and symptoms in these patients included decreasing visual acuity $(60 \%)$, a visible iris or ciliary body mass $(60 \%)$, ocular injection $(48 \%)$, and ocular pain $(44 \%)$. Secondary glaucoma was noted in 7 patients $(28 \%)$ with anterior segment metastases. Both open-angle and angle-closure mechanisms of pressure elevation were implicated.

The importance of iridocyclitis as a presenting sign of intraocular metastatic malignancy was first

Table 1 Malignancies with reported metastases to the iris or ciliary body

\begin{tabular}{ll}
\hline Primary site & References \\
\hline Lymphoma & 11 \\
Leukaemia & $12-19$ \\
Cutaneous malignant melanoma & 20 \\
Breast carcinoma & \\
Bronchial carcinoma & $3,8,21$ \\
Pancreatic carcinoma & $19-30$ \\
Bronchial carcinoid & 31 \\
Thyroid carcinoma & 32 \\
Hypernephroma & 3 \\
Carcinoma of the rectum & 3 \\
Gastric carcinoma & 32 \\
Prostatic carcinoma & 32 \\
Squamous cell carcinoma of the lip & 26 \\
\hline
\end{tabular}




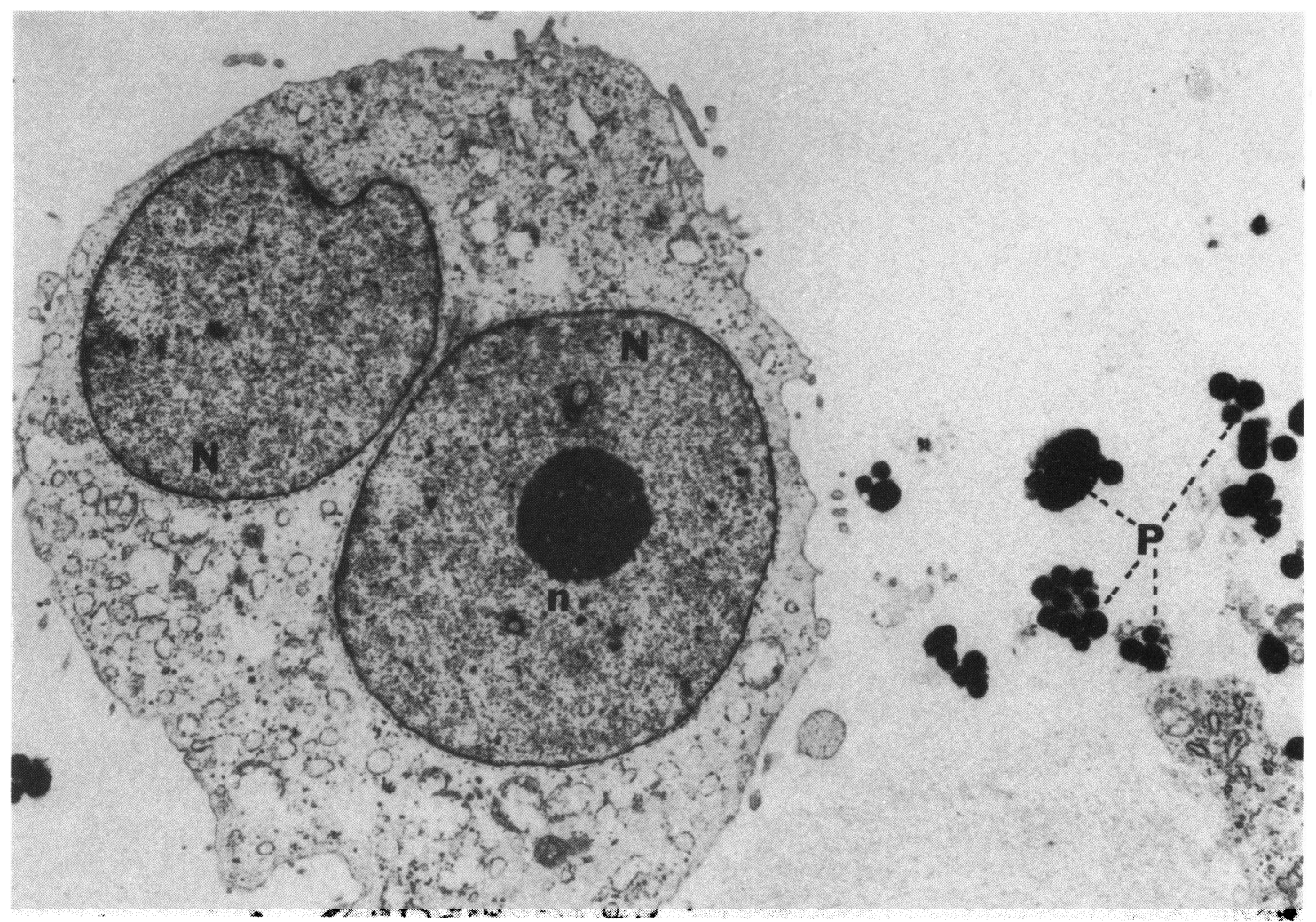

Fig. 11 Occasional binucleate cells are identified; free iris pigment is present $(\mathrm{P}) .(\mathrm{N}$, nucleus; $\mathrm{n}$, nucleolus $)($ TEM, $\times 4420)$.

acknowledged by Kreibig ${ }^{10}$ and has subsequently been recognised by other investigators. ${ }^{324-26} 28293334$ Marked anterior uveitis occurring in this setting may result in an elevation of intraocular pressure ${ }^{33}$ as in our patient, mimicking uveitic glaucoma. Intraocular inflammation secondary to anterior segment metastasis may be severe enough to prompt a clinical diagnosis of infectious endophthalmitis. ${ }^{28}$ Indeed a precise clinical diagnosis of iridocyclitis secondary to malignancy is often difficult, and the diagnosis may accordingly be delayed. In the study of Ferry and Font, for example, iridocyclitis occurred in $40 \%$ of patients with anterior segment involvement; disseminated malignancy was suspected initially in fewer than half of these patients. ${ }^{3}$ The development of hyphaema in association with iridocyclitis is, according to several authors, ${ }^{24}$ particularly suggestive of underlying malignancy, and this observation may be helpful in the early diagnosis of anterior segment metastasis.

The value of paracentesis in the diagnosis of malignancy in the setting of iridocyclitis of uncertain aetiology was discussed by Remky in $1961^{35}$ and by Morgan et al. in $1970 .{ }^{29}$ The latter authors described a 64-year-old with chronic iridocyclitis and secondary glaucoma unresponsive to vigorous therapy. Paracentesis with cytological examination of the aspirate yielded a diagnosis of mucoepidermoid carcinoma. Subsequent re-examination of the patient revealed a previously unsuspected lung tumour. Although paracentesis may thus provide an effective means of diagnosis of a life-threatening systemic malignancy, it should be noted that paracentesis and cytological studies have been negative in at least one patient with iridocyclitis and histopathologically confirmed anterior segment metastasis. ${ }^{36}$ In our experience at least a $3+$ cellular reaction is necessary for the diagnosis of metastatic iridocyclitis by Millipore filtration techniques. In addition paracentesis carries a small risk of extraocular spread of malignancy. ${ }^{23}$ Nevertheless, paracentesis remains an important means of diagnosing metastatic tumour to the eye in patients with and without a prior history of malignancy.

Several modes of preparation of aqueous specimens for cytological examination are available. Millipore filtration ${ }^{5}$ has been a useful means of recovering cellular material from fluid specimens for 
examination. This technique is limited by variations in staining characteristics and high background staining of the filter. Centrifugation in celloidin bags permits recovery of sedimented cellular material, which may then be embedded in paraffin and processed in a standard fashion. ${ }^{6}$ While this approach allows flexibility in the choice of stains and also permits subsequent preparation of additional slides for special examination, it is somewhat more timeconsuming than Millipore filtration or cytocentrifugation. Cytocentrifugation is a standard technique in the cytological analysis of cerebrospinal fluid and urine samples, and has been adapted to the study of aqueous and vitreous specimens. ${ }^{7}$ A cytocentrifugation preparation can be available for examination within 30 minutes. Furthermore this technique affords excellent recovery of cellular material from dilute specimens, and promises to be of special value to the ophthalmic cytopathologist, who often must analyse a specimen of limited volume. The cytocentrifugation preparation obtained from $0.1 \mathrm{ml}$ of aqueous, for example, was the basis for the diagnosis of metastatic adenocarcinoma in the present case.

Therapeutic efforts directed at anterior segment metastases have included surgery (removal of tumour nodules by iridocyclectomy ${ }^{31}$ ) and radiation therapy. ${ }^{15}{ }^{17}$ Chemotherapy required for control of systemic disease has also been effective in limiting ocular symptomatology in a patient with small-cell carcinoma of the lung metastatic to the iris. ${ }^{27}$

\section{References}

1 Albert DM, Rubinstein RA, Scheie HG. Tumor metastasis to the eye. Part I. Incidence in 213 adult patients with generalized malignancy. Am J Ophthalmol 1967; 63: 72-3.

2 Bloch RS, Gartner S. The incidence of ocular metastatic carcinoma. Arch Ophthalmol 1971; 85: 673-5.

3 Ferry AP. The biological behavior and pathological features of carcinoma metastatic to the eye and orbit. Trans Am Ophthalmol Soc 1973; 71: 373-425.

4 Ferry AP, Font RL. Carcinoma metastatic to the eye and orbit. I. A clinicopathologic study of 227 cases. Arch Ophthalmol 1973; 92: $276-86$.

5 Delvecchio PR, DeWitt SH, Bovelli JI, Ward JR, Wood, TA Jr, Malmgren RA. Application of millipore filtration technique to cytologic material. J Natl Cancer Inst 1959; 22: 427-31.

6 Engel H, de la Cruz ZC, Jiminez-Abalahin LD, Green WR, Michels RG. Cytopreparatory techniques for eye fluid specimens obtained by vitrectomy. In preparation.

7 Watson P. A slide centrifuge: an apparatus for concentrating cells in suspension onto a microscope slide. J Lab Clin Med 1966; 68: 494-501.

8 Proctor FJ, Verhoeff FH. A case of metastatic carcinoma of the iris. Arch Ophthalmol 1907; 36: 47-51.
9 Duke-Elder S, Perkins ES. Diseases of the uveal tract. In: DukeElder S, ed. System of ophthalmology. London: Kimpton, 1966 9: 816.

$10 \mathrm{Kreibig} \mathrm{W.} \mathrm{Üeber} \mathrm{karzinommetastasen} \mathrm{im} \mathrm{Auge.} Z$ Augenheilkd 1937; 93: 278-92.

11 Guzak SV Jr. Lymphoma as a cause of hyphema. Arch Ophthalmol 1970; 84: 229-31.

12 Masera G, Carnelli V, Uderzo C, Toselli C, Lasagni $F$, Lambertenghi $\mathrm{E}$. Leukaemic hypopyon in ALL after interruption of therapy. Arch Dis Child 1979; 54: 73-4.

13 Perry HD, Mallen FJ. Iris involvement in granulocytic sarcoma. Am J Ophthalmol 1979; 87: 530-2.

14 Rowan PJ, Sloan JB. Iris and anterior chamber involvement in leukemia. Ann Ophthalmol 1976; 8: 1081-5.

15 Jonnson SS, Ware CF. Iris involvement in leukaemia. $\mathrm{Br} \mathrm{J}$ Ophthalmol 1973; 57: 320-4.

16 Martin B. Infiltration of the iris in chronic lymphatic leukaemia. Br J Ophthalmol 1968; 52: 781-5.

17 Fonken HA, Ellis PP. Leukemic infiltrates in the iris. Successful treatment of secondary glaucoma with $x$-irradiation. Arch Ophthalmol 1966; 76: 32-6.

18 Allen RA, Straatsma BR. Ocular involvement in leukemia and allied disorders. Arch Ophthalmol 1961; 66: 490-508.

19 Glaser B, Smith JL. Leukaemic glaucoma. Br J Ophthalmol 1966; 50: $92-4$.

20 Hirst LW, Reich J, Galbraith JEK. Primary cutaneous malignant melanoma metastatic to iris. Br J Ophthalmol 1979; 63: 165-8.

21 Freeman TR, Friedman AH. Metastatic carcinoma of the iris. Am J Ophthalmol 1975; 50: 947-52.

22 Barishak YR, Barah M, Lazar M. Metastatic tumor of the iris: a case report. Ann Ophthalmol 1978; 10: 1191-3.

23 Middleton WH. Diagnosis of metastatic tumors of the anterior ocular segment. Am J Ophthalmol 1952; 35: 1329-34.

24 Duke JR, Kennedy JJ. Metastatic carcinoma of the iris and ciliary body. Arch Ophthalmol 1958; 60: 1092-103.

25 Mayer W, Ray ES. Metastatic carcinoma of the iris and ciliary body. Am J Ophthalmol 1955; 39: 37-43.

26 Cury D. Metastatic carcinoma of the iris. Am J Ophthalmol 1958; 45: $221-4$

27 Sierocki JS, Charles NC, Schatrank M, Wittes RE. Carcinoma metastatic to the anterior ocular segment: response to chemotherapy. Cancer 1980; 45: 2521-3.

28 Levine RA, Williamson DE. Metastatic carcinoma simulating post-operative endophthalmitis. Arch Ophthalmol 1970; 83: $59-60$.

29 Morgan WE III, Malmgren RA, Albert DM. Metastatic carcinoma of the ciliary body simulating uveitis. Arch Ophthalmol 1970; 83: 54-8.

30 Barsky D. Unusual tumor of the iris: a rare initial clinical manifestation of metastatic adenocarcinoma of the tail of the pancreas. Ann Ophthalmol 1978; 10: 1539-43.

31 Rodrigues MM. Shields JA. Iris metastasis from a bronchial carcinoid tumor. Arch Ophthalmol 1978; 96: 77-83.

32 Sanders TE. Metastatic carcinoma of the iris. Am J Ophthalmol 1938; $21: 646-50$.

33 Reese AB. Tumors of the eye. 3rd ed. New York, Harper and Row: 1976: 423

34 Duke-Elder S, Perkins ES. Diseases of the uveal tract. In: DukeElder S, ed. System of ophthalmology. London: Kimpton, 1966: 9: $925-6$.

35 Remky H. Tumorzellen im Kammerwasser. Klin Monatsbl Augenheilkd 1961; 138: 643-9.

36 Denslow GT, Kielar RA. Metastatic adenocarcinoma to the anterior uvea and increased CEA levels. Am J Ophthalmol 1978; 85: $363-7$. 